\title{
Relações entre significado do trabalho e percepção de suporte para pessoas com deficiência em organizações brasileiras
}

\author{
Raissa Pedrosa Gomes Tette \\ Maria Nivalda de Carvalho-Freitas \\ Marcos Santos de Oliveira \\ Universidade Federal de São João del Rei
}

\begin{abstract}
Resumo
Mediante a obrigatoriedade de contratação de pessoas com deficiência advinda com a Lei de Cotas, o processo de inclusão de pessoas com deficiência (PcD) nas organizações brasileiras tem sido permeado por desafios, tanto para as empresas quanto para as próprias PcD. Este trabalho foi desenvolvido com o propósito de verificar a influência da percepção de suporte social e de suporte organizacional no significado do trabalho para $\mathrm{PcD}$. As investigações foram realizadas com uma amostra de 169 pessoas com deficiência que trabalham em organizações de diversos segmentos nas diferentes regiões do Brasil. Concluiu-se que as categorias que melhor descrevem o significado do trabalho concreto das pessoas com deficiência estão associadas à garantia de condições econômicas de sobrevivência e de sustento pessoal e familiar, da estabilidade no emprego, do salário e do progresso social. As percepções de 'Suporte Social no Trabalho' e de 'Suporte Organizacional' são variáveis preditivas do Significado do Trabalho.
\end{abstract}

Palavras-chave: inclusão; deficiência; suporte social no trabalho; suporte organizacional.

\begin{abstract}
Relationship between meaning of work and perception of support for people with disabilities in Brazilian organizations. Regarding to the obligation to employ disabled people, due to the Quotas Act, the inclusion process of people with disability (PWD) in Brazilian organizations has been permeated by challenges, both for the companies and for the PWD. This work has been conducted with the purpose of verifying the influence of social support perception and of organizational support in the work meaning to PWD. The investigations were carried out with a sample of 169 disabled people who work in companies of several segments from different regions of the country. It was concluded that the categories that better describe the concrete work meaning of these people, are related to the guarantee of survival economic conditions as well as personal and family support, job stability, salary and social progress. The perceptions of 'Social Support at Work' and 'Organizational Support' are predictive variables of Work Meaning.
\end{abstract}

Keywords: inclusion; disability; social support at work; organizational support.

\section{Resumen}

Relaciones entre significado de trabajo y percepción del apoyo para personas con discapacidad en organizaciones brasileras. Mediante la obligación de contratación de personas con discapacidad proveniente de la Lei de cuotas, el proceso de inclusión de personas con discapacidad (PcD) en las organizaciones brasileras han sido impregnado por los desafíos, tanto para las empresas como para las propias PcD. Este trabajo fue desarrollado con el propósito de verificar la influencia de la percepción del apoyo social y del apoyo organizacional en el significado del trabajo para PcD. Las investigaciones fueron realizadas con una muestra de 169 personas con discapacidad que trabajan en organizaciones de diversos segmentos en diferentes regiones del Brasil. Se concluyó que las categorías que mejor describen el significado de trabajo concreto de las personas con discapacidad están asociadas a la garantía de condiciones económicas de sobrevivencia y de sustento personal y familiar, de la estabilidad en el empleo, del salario y del progreso social. Las percepciones de "Apoyo Socia 1 en el Trabajo" y de "Apoyo Organizacional" son variables predictivas del Significado de Trabajo.

Palabras clave: inclusión; discapacidad; significado de trabajo; apoyo social en el trabajo; apoyo organizacional. 
$\mathrm{E}^{?}$ m levantamento da Organização Internacional do Trabalho (OIT, 2009) constatou-se que cerca de $10 \%$ da população mundial é composta por pessoas com deficiência (PcD), sendo que $72 \%$ delas estão em idade produtiva. No Brasil, segundo dados do censo realizado em 2010, pelo Instituto Brasileiro de Geografia e Estatística (IBGE), existem 45,6 milhões de pessoas com pelo menos um tipo de deficiência, o que representa $23,9 \%$ da população brasileira.

A Secretaria Internacional do Trabalho (2006) afirma que uma pessoa com deficiência possui reduzidas perspectivas de obter um emprego apropriado, reassumi-lo, mantê-lo e nele progredir, principalmente em função da existência de barreiras sociais e arquitetônicas presentes no mundo do trabalho (Schur, Kruse, \& Blanc, 2005). No entanto, nos últimos anos, inúmeras mudanças sociais vêm ocorrendo na busca pela igualdade de oportunidade para todos, e vêm crescendo também o número de movimentos em defesa dos direitos das pessoas com deficiência, suscitando mudanças nas legislações dos países. Visando garantir a inserção de PcD no mercado formal de trabalho, o governo brasileiro sancionou a Lei n. 8.213 (1991), conhecida como Lei de Cotas. Essa Lei estipula que qualquer empresa privada e com 100 ou mais empregados, deve preencher de 2 a $5 \%$ dos seus cargos com pessoas com deficiência. Também as organizações públicas devem ter PcD em seu quadro de funcionários, garantia esta prevista na Lei n. 8.112 (1990), que estabelece a reserva de até $20 \%$ das vagas oferecidas em concursos para as pessoas com deficiência.

Entretanto, a implementação da política nacional de cotas empregatícias não se deu de forma imediata (Ribeiro \& Carneiro, 2009). Além da descrença e do desconhecimento de sua capacidade laboral, o ambiente de trabalho muitas vezes não é acessível para pessoas com deficiência (Tanaka \& Manzini, 2005). Mediante a obrigatoriedade advinda com a Lei de Cotas, as organizações começaram a executar as contratações sem nenhum tipo de planejamento. Pesquisas indicam que a maior parte dos trabalhadores com deficiência são alocadas em funções específicas, apenas para garantir o cumprimento da Lei, o que pode sugerir falta de experiência por parte de gestores e colegas de trabalho, falta de investimento na capacitação das $\mathrm{PcD}$, descrença quanto à capacidade de liderar ou acomodação das próprias PcD na função (Pereira, Del Prette, \& Del Prette, 2008; Tanaka \& Manzini, 2005;Violante \& Leite, 2011), apesar do trabalho ter um papel significante na vida das PcD (Gomes, 2009).

O trabalho e sua centralidade na vida das pessoas e da sociedade é objeto de discussão de várias vertentes de estudo, mas a Psicologia começou a tratar sistematicamente a questão do significado do trabalho a partir da década de 1980. O afloramento do interesse neste assunto foi incentivado por vários fenômenos, dentre eles o surgimento de novos modelos de organização do trabalho, mudanças nas relações trabalhistas, polêmicas em torno do papel estruturante do trabalho, crescimento no setor de serviços e mudanças epistêmicas na Psicologia (Borges \& Yamamoto, 2010).

Brief e Nord (1990), partindo de uma visão do trabalho como dinâmico e mutante, que não possui uma essência uni- versal, focalizam a importância de compreender o processo histórico como um caminho necessário para a compreensão da incorporação dos valores do trabalho e de seus componentes ideológicos. Para Borges e Tamayo (2001), o conceito do significado do trabalho é caracterizado como uma cognição subjetiva e social que varia individualmente, na medida em que deriva do processo de atribuir significados e, ao mesmo tempo, apresenta aspectos socialmente compartilhados, associados às condições históricas da sociedade. Portanto, o significado do trabalho revela em si a contemporaneidade do sujeito e possui dimensões contingenciais associadas ao contexto em que o trabalho ocorre (Borges \& Yamamoto, 2010).

Além disso, uma pesquisa identificou que quando garantida a satisfação com fatores relacionados ao contexto laboral, as PcD têm resultados de satisfação e comprometimento no trabalho similares aos das demais pessoas (Carvalho-Freitas, Silva, Farias, Oliveira, \& Tette, 2013). Outro estudo identificou a importância das organizações no processo de socialização das pessoas com deficiência, tendo verificado que as PcD assumem comportamentos mais proativos quando percebem que ocorrem ações de adequação nas organizações (CarvalhoFreitas et al., 2010).

Neste âmbito, pressupõe-se que a preocupação da organização em acolher as pessoas que a compõem pode influenciar no significado que elas atribuem ao trabalho. Para isso, o suporte no trabalho - caracterizado pelo suporte social e organizacional - desempenha um papel fundamental, podendo atuar de forma direta ou indireta na manutenção do bem-estar dos trabalhadores (Siqueira \& Gomide Jr., 2008) e possivelmente no significado atribuído ao trabalho. Assim, o presente estudo tem por objetivo identificar se o significado que a pessoa com deficiência atribui ao seu trabalho tem relação com a percepção de suporte social e organizacional percebido.

\section{O significado do trabalho}

Brief e Nord (1990) explicam que o indivíduo insere suas marcas nos modos de se conceber o trabalho. Os autores enfatizam a importância dos fatores históricos na atribuição do significado do trabalho, explicando que este construto possui um caráter dinâmico, inacabado e socialmente inserido, visto que é afetado por um complexo e dinâmico sistema social. Borges (1998) explica ainda que o significado do trabalho é tanto uma estrutura cognitiva como subjetiva, já que está ligada às crenças, valores e atitudes individuais do sujeito. Ao mesmo tempo, sugere que é uma construção histórico-social. A autora explica que em seu curso de formação, o indivíduo sofre a todo o momento interação com os demais membros da sociedade, fazendo com que caracterize o trabalho de forma variável. Dessa forma, além de dependente da formação individual, o significado do trabalho é construído coletivamente, a partir das interações sociais, acontecimentos históricos e do contexto em que os indivíduos estão inseridos.

Uma investigação realizada pela Equipe MOW (1987) impulsionou a condução de pesquisas que identificassem as variáveis que explicam os significados que os sujeitos atribuem ao trabalho. A bibliografia tem convergido a assumi-lo como um 
construto multifacetado (Brief \& Nord, 1990; MOW, 1987), entretanto, não há consenso quanto à identificação dessas facetas. Em consonância com a proposta dos autores Borges e Tamayo (2001), e por tratar-se de modelo validado em pesquisas anteriores realizados no Brasil (Borges \& Alves Filho, 2003; Borges \& Yamamoto, 2010; Borges, Tamayo \& Alves Filho, 2005), nesta pesquisa foram utilizadas as facetas por eles propostas, nos seguintes termos:

(a) Centralidade do trabalho: grau de importância que o trabalho possui na vida de uma pessoa, quando comparado a outras dimensões da vida (família, lazer, religião e comunidade). Conceito incorporado da Equipe MOW (1987), que considera essa dimensão como o grau de importância que o trabalho possui na vida de uma pessoa em um dado momento; (b) Atributos valorativos e descritivos do trabalho: dimensões que expressam a percepção do trabalhador em relação à realidade concreta e idealizada do trabalho respectivamente. Os atributos descritivos estão relacionados ao trabalho concreto (o que o trabalho é), enquanto os atributos valorativos versam sobre o que o trabalho deve ser, e é formado por valores, crenças e ideologias presentes na sociedade (Borges \& Tamayo, 2001); (c) Hierarquia dos atributos: consiste na organização dos atributos valorativos e descritivos segundo o grau de importância atribuída a eles.

\section{Suporte social no trabalho}

A definição de suporte social provém da definição de rede social. As redes sociais são definidas como o conjunto de pessoas com as quais um indivíduo se relaciona e se identifica socialmente em sua vida Assim, essas pessoas funcionam como fontes de apoio diante de dificuldades e adversidades e permitem ao indivíduo construir e manter sua identidade social (Cohen, 2004).

Rodriguez e Cohen (1998) categorizaram os recursos disponibilizados pelas redes em três dimensões: suporte emocional, suporte instrumental, e o suporte informacional, as quais estão relacionadas aos diferentes tipos de apoio que alguém pode receber de sua rede social.

Conforme Gomide Jr., Guimarães e Damásio (2004; 2008), a percepção de suporte emocional no trabalho refere-se às crenças dos funcionários de que na organização para a qual trabalham existem pessoas em que se pode confiar, que se mostram preocupadas umas com as outras, que se valorizam e que se gostam.

O suporte social informacional, por sua vez, inclui informações e orientações disponibilizadas por integrantes da rede social. De acordo com Cohen (2004), ele envolve o fornecimento de informações relevantes, destinadas a auxiliar o indivíduo a lidar com as dificuldades. Gomide Jr. et al., (2004, 2008) salientam que o suporte informacional no trabalho refere-se à crença, por parte do funcionário, de que a organização possui uma rede de comunicações comum, através da qual são veiculadas informações precisas e confiáveis.

Por último, há o suporte social instrumental, relacionado aos auxílios tangíveis ou materiais. Esta percepção está associada à crença do indivíduo de que a empresa fornece insumos materiais, financeiros, técnicos e gerenciais necessários à realização de suas tarefas (Gomide Jr. et al., 2004; 2008).

\section{Suporte organizacional}

Os empregados desenvolvem com a organização uma relação de troca social, marcada por expectativas de reciprocidade, segundo as quais as pessoas devem ajudar aqueles que os ajudam (Eisenberger, Huntington, Hutchison, \& Sowa, 1986). Gouldner (1960) nomeou este 'sentimento obrigatório de retribuição' como princípio da reciprocidade. Para o autor, este é o preceito que sustenta todas as relações de troca social, uma vez que institui um contrato psicológico ancorado numa base de confiança mútua nas quais se acredita que posteriormente às doações efetivadas pelo emissor, sucederia um retorno por parte do receptor.

Um contrato psicológico baseado em expectativas de troca e benefícios mútuos é também estabelecido entre trabalhador e organização. Assim, enquanto a organização tem obrigações legais, financeiras e morais para com seus membros, os empregados, por sua vez, retribuem à organização com seus esforços, bom desempenho e lealdade (Oliveira-Castro, Pilati, \& Borges-Andrade, 1999). Em função do tipo de tratamento recebido por uma parte, revela-se a tendência de haver reciprocidade da outra parte, podendo levar a resultados benéficos para ambos (Rhoades \& Eisenberger, 2002).

Segundo Eisenberger et al. (1986), o fenômeno dos trabalhadores desenvolverem percepções acerca da qualidade do tratamento que recebem da organização, em retribuição ao esforço que despendem no trabalho, é chamado de percepção de suporte organizacional, e baseia-se na frequência, intensidade e sinceridade das manifestações organizacionais de aprovação, elogio, retribuição material e social ao esforço dos seus recursos humanos.

\section{Método}

A coleta de dados foi realizada com uma amostra de conveniência composta por 169 pessoas com deficiência que trabalham em empresas de diversos segmentos nas diferentes regiões do Brasil. A região Sudeste contribuiu com $63,3 \%$ dos participantes, os demais participantes estavam distribuídos pelo Nordeste (13,0\%), a região Sul (12,4\%), o Centro-Oeste $(5,9 \%)$ e a Região Norte, com 5,3\% de respondentes. A amostra foi constituída por $63,3 \%$ de participantes do sexo masculino e $36,7 \%$ do sexo feminino. Esses índices de resposta relacionados ao sexo corroboram pesquisa divulgada na Relação Anual de Informações Sociais - RAIS (Ministério do Trabalho e do Emprego - MTE, 2011) com trabalhadores de empregos formais no Brasil, a qual registrou que os homens com deficiência têm uma representatividade maior no mercado de trabalho.

Em relação à faixa etária, a maior participação neste estudo concentrou-se no grupo de pessoas com idades entre 31 a 50 anos $(65,1 \%)$. Os dados da RAIS para as pessoas com deficiência em geral demonstram que há um predomínio de profissionais na faixa etária de 18 a 29 anos (35\%). Quanto 
ao estado civil, $52,1 \%$ declararam-se casados, $36,1 \%$ solteiros, $7,7 \%$ são divorciados e $4,1 \%$ responderam 'outro'. Quanto ao tipo de deficiência, há uma significativa prevalência de pessoas com deficiência física (61,5\%), seguidas de PcD auditiva (21,3\%) e visual (17,2\%).

Os profissionais trabalham prioritariamente no desempenho de função administrativa/operacional (39,6\%) ou técnica (37,9\%). As funções administrativa/operacional compreendem, por exemplo, os cargos de assistente administrativo, auxiliar de operações, assistente de atendimento, etc. As funções de nível técnico se referem àquelas que exigem uma formação técnica específica, como técnico em segurança, técnico bancário ou técnico em manutenção. O grupo de profissionais no nível técnico profissional (10,7\%) compreende as funções que exigem curso superior, como arquitetos, engenheiros e psicólogos. Finalmente, no grupo de gestão estão funções que envolvem liderança, correspondendo às atuações de supervisores ou gerentes $(11,8 \%)$. Observa-se, dessa forma, a predominância de PcD em cargos administrativos e operacionais em detrimento, principalmente, de cargos de gestão, confirmando dados de pesquisa realizada pelo Instituto Ethos (2010).

As pessoas com deficiência foram contatadas e convidadas a responder os seguintes questionários: questionário sociodemográfico, a Escala de Percepção de Suporte Social no Trabalho [EPSST] (Gomide Jr. et al., 2004), a Escala de Percepção de Suporte Organizacional [EPSO] (Siqueira, 1995). As respostas do EPSST e do EPSO foram emitidas numa escala Likert de cinco pontos, nos seguintes termos: 1 = discordo totalmente, 2 = discordo, 3 = indiferente, 4 = concordo e 5 = concordo totalmente. Além disso, também foram respondidas questões sobre centralidade do trabalho, adaptadas do Grupo MOW (1987) por Soares (1992) e o Inventário de Motivação e do Significado do Trabalho [IMST] (Borges \& Alves-Filho, 2003). A parte do IMST contemplada na presente pesquisa possui duas dimensões: a) quanto o trabalho implica o resultado indicado idealmente (atributos valorativos); e b) quanto julga que ocorre realmente o resultado indicado (atributos descritivos). O respondente deve atribuir a cada item um valor numa escala Likert que varia de 0 a 4 pontos conforme o grau de concordância.

A coleta de dados foi realizada por meio de contato com empresas nacionais que contratam pessoas com deficiência e contato com um SINE (Sistema Nacional de Emprego) especializado em pessoas com deficiência. Além disso, solicitou-se que cada respondente do estudo enviasse o link da pesquisa para outras PcD do seu círculo de conhecimento. Os questionários foram enviados para as pessoas com deficiência por meio de e-mails contendo o link do site no qual os questionários estavam hospedados.

A análise dos dados envolveu a utilização de modelos estatísticos, com base na utilização do programa SPSS for Windows, compreendendo as seguintes técnicas: estatística descritiva (análise das médias, desvio padrão e percentual de frequência), visando a descrição da centralidade atribuída ao trabalho, percepção de suporte social e percepção de suporte organizacional; Smallest Space Analysis (Análise SSA), para identificar a estrutura de dados dos fatores descritivos e valorativos do significado do trabalho; análise de Cluster, para identificar se as pessoas com deficiência podem ser agrupadas em diferentes conjuntos (padrões) segundo os significados atribuídos ao trabalho; alfa de Cronbach, para verificar a consistência interna dos itens identificados como sendo de um fator); teste $t$ de Student, para verificar quão provável a diferença entre duas condições sociodemográficas; análise de Variância (ANOVA), para verificar se existiam diferenças significativas entre as médias dos grupos em função dos fatores sociodemográficos (com três ou mais opções de resposta); e regressão múltipla, para verificar se existia relação de dependência entre o suporte social e organizacional e o significado do trabalho real. A amostra foi integralmente utilizada nas análises dos dados. Todos os procedimentos éticos foram resguardados.

\section{Resultados e discussão}

\section{O significado do trabalho}

Os participantes apresentaram elevado nível de centralidade do trabalho $(25,21)$, manifestando uma atribuição de importância da centralidade relativa do trabalho apenas inferior à esfera da família $(37,46)$. A centralidade absoluta também é alta $(5,59$, com desvio-padrão de 1,34$)$, ratificando uma tendência nacional (Borges \& Alves Filho, 2003; Borges \& Yamamoto, 2010). Na década de 90, os resultados no Brasil mostravam uma centralidade menos elevada (Borges, 1998; Soares, 1992).

Os resultados da aplicação do IMST (Borges \& Alves-Filho, 2003), utilizando a técnica da Análise da Estrutura de Similaridades (Smallest Space Analysis - SSA), permitiram agrupar sete fatores de atributos descritivos e quatro fatores dos atributos valorativos.

Assim, os fatores dos atributos descritivos foram designados da seguinte forma: 'Sobrecarga e Desumanização' ( $\alpha=$ $0,71 / M=2,27$ ), 'Oportunidade e Justiça no trabalho' ( $\alpha=$ $0,86 / M=2,34)$, 'Participação e Recompensa' ( $\alpha=0,75 / M$ = 2,63), 'Segurança e Acolhimento' ( $\alpha=0,86$ / Média: 2,83), 'Condições de Trabalho' ( $\alpha=0,87 / M=3,13)$, 'Sobrevivência Pessoal e Familiar ( $\alpha=0,85$ / Média: 3,26) e 'Carga de Trabalho' ( $\alpha=0,75 / M=3,20)$.

Os fatores dos atributos valorativos foram agrupados da seguinte maneira: 'Justiça e Realização' ( $\alpha=0,79 / M=3,65)$, 'Dignidade' ( $\alpha=0,81 / M=3,76)$, 'Reconhecimento' ( $\alpha=0,84$ / $M=3,69)$ e 'Ocupação e Sobrecarga' $(\alpha=0,85$ / $M=3,04)$.

As diferenças encontradas entre os fatores descritivos e os fatores valorativos do significado do trabalho mostram que a realidade do trabalho difere do modelo ideal de trabalho almejado pelas PcD, diferenças também encontradas entre trabalhadores sem deficiência (Borges \& Yamamoto, 2010; Borges, Tamayo \& Alves Filho, 2005).

Para a amostra, o trabalho concreto (atributos descritivos) é prioritariamente percebido como uma forma de garantir a sobrevivência pessoal e familiar (fator 'Sobrevivência Pessoal 
e Familiar': média 3,26, numa escala de 0 a 4) e como ocupação, obrigação de realizar tarefas repetidas e cumprir responsabilidades (fator 'Carga de Trabalho': média 3,20). As pessoas com deficiência relataram ainda uma tendência em reconhecer a presença de condições necessárias para o desenvolvimento das atividades, por meio de equipamentos, assistência, segurança e amparo social (fator 'Condições de Trabalho': média 3,13 ) e possibilidade de desenvolver as habilidades interpessoais e boa comunicação com os chefes (fator 'Segurança e Acolhimento': média 2,83). Esses resultados assemelham-se aos encontrados por Vilela (2003) e Varella (2006), que identificaram que bancários sem deficiência também percebem o trabalho principalmente como oportunidade de independência econômica e sobrevivência, e que existem as condições necessárias para o desenvolvimento das atividades através de equipamentos e assistência.

Com médias menores, o trabalho concreto também foi descrito como um ambiente no qual se observa sentimento de prazer pela realização das tarefas, oportunidade de aprendizado e reconhecimento (fator 'Participação e Recompensa': $M=2,63$ ) e como lugar com boas condições de higiene, assistência, equidade de direitos entre colegas, provisão salarial e equilíbrio entre esforços e recompensas (fator 'Oportunidade e Justiça no Trabalho' $M=2,34$ ). Por outro lado, a realização das atividades está também implicando desgaste gerado pelo esforço físico despendido e pela repetição de tarefas (fator 'Sobrecarga e Desumanização': $M=2,27$ ).

Em relação aos atributos valorativos, a amostra estima prioritariamente a independência financeira e o retorno econômico merecido (fator 'Dignidade: $M=3,76$ numa escala de 0 a 4). Para as pessoas com deficiência, então, o trabalho ideal está associado a uma organização que cumpre as normas para com o trabalhador, provê assistência e segurança, oferece salários justos e possui boa comunicação, resultados semelhantes aos encontrados por Vilela (2003) e Varella (2006) com universitários e bancários não $\mathrm{PcD}$, respectivamente. O fator 'Reconhecimento', com média 3,69, mostra que as PcD também valorizam um trabalho que dá oportunidade de expressão da criatividade, capacidade de tomar decisões e prazer pela realização das tarefas. Além disso, um trabalho que garante boas condições de equipamentos, assistência, conforto, equidade de direitos entre colegas, equilíbrio entre esforços e recompensas (fator 'Justiça e Realização: $M=3,65$ ) também é relevante para o trabalhador. Com média menor, segue o fator 'Ocupação e Sobrecarga', com $M=3,04$, caracterizado pela repetição diária de tarefas, por proporcionar ocupação, esforços físicos e altas exigências da organização para com o trabalhador.

Foram identificados três grandes agrupamentos (clusters) em função dos fatores do significado do trabalho identificados na pesquisa. O maior grupo, denominado 'Instrumental econômico', compreendeu 78 participantes, o que corresponde a $46 \%$ dos respondentes. Estas pessoas apresentam médias moderadas nos fatores descritivos, sendo a mais baixa no item 'Oportunidade e Justiça no trabalho' ( $M=2,17$ : os participantes desse grupo percebem seu trabalho cotidiano com poucas condições de higiene, conforto e segurança) e a mais elevada para o item 'Sobrevivência pessoal e familiar' ( $M=3,13$ : o trabalho, de forma geral, garante condições de sobrevivência e de sustento pessoal e familiar). Nos atributos valorativos, destacam-se médias um pouco mais elevadas ( $M$ variando de 2,95 a 3,72 ), mas com diferenças pouco significativas se comparadas às médias dos atributos descritivos, o que pode caracterizar um grupo com características mais apáticas e indiferentes ao domínio de sua atuação profissional. Esse grupo era formado predominantemente por pessoas com deficiência auditiva. A configuração desse agrupamento (o maior entre as PcD desse estudo) reflete um significado do trabalho relacionado mais estritamente à sobrevivência familiar, e sem uma expectativa do trabalho muito idealizada (diferente de pesquisas com não PcD, como Vilela, 2003; Varella, 2006; Borges, Tamayo, \& Alves Filho, 2005; Borges \& Yamamoto, 2010). Essa atribuição de significados é predominante entre pessoas com deficiência auditiva que, em princípio, são impedidas de ter uma possibilidade maior de compartilhamento do que Borges (1998) denomina como construção coletiva dos significados atribuídos ao trabalho. Nesse sentido, esse resultado também revela as dificuldades da sociedade em minimizar os problemas de comunicação das pessoas com deficiência auditiva.

Um segundo grupo com grande contingente de participantes ( 73 pessoas ou $43 \%$ da amostra), denominado 'Realizados', contempla, de uma maneira geral, as pessoas que tendem a atribuir escores elevados para todos os fatores integrantes das análises (médias entre 2,09 e 3,85). A menor média encontrada foi atribuída ao fator descritivo 'Sobrecarga e Desumanização' $(M=2,09)$. Nos fatores valorativos, a média de todos foi elevada ( $M$ acima de 3,75 ). Esse grupo era predominantemente formado por pessoas com deficiência física.

Finalmente, caracterizou-se um terceiro padrão menos robusto, 'Insatisfeitos apáticos', englobando 18 participantes ou $10 \%$ da amostra total. De uma maneira geral, este grupo se caracteriza por médias menores em todos os fatores, principalmente nos fatores descritivos 'Oportunidade e Justiça no Trabalho' $(M=1,22)$ e 'Participação e Recompensa' $(M=1,31)$. É o grupo com menor escolaridade e menor diferença de escores entre atributos descritivos e valorativos, o que mostra que estes participantes não possuem um ideal de trabalho muito diferente do trabalho real. Esse grupo era formado predominantemente por pessoas com deficiência auditiva. Considerando que este constitui o grupo com menor escolaridade, se supõe que trabalhadores menos instruídos costumam ter aspirações limitadas, contudo, deve-se atentar que estas serão tanto mais limitadas quanto mais empobrecidos forem o contexto e a realidade do mundo do trabalho (Borges \& Tamayo, 2001).

Verifica-se que os significados atribuídos ao trabalho variam entre as deficiências, sendo as pessoas com deficiência física as que se encontram no agrupamento de melhor avaliação dos diversos aspectos de significado do trabalho. Suzano (2011) e Ribeiro e Carneiro (2009) alertam que o tipo de deficiência pode favorecer ou limitar as chances de uma determinada PcD alcançar uma vaga de trabalho formal, justificando que as empresas buscam contratar pessoas com deficiência que não requerem adaptações no ambiente e que não possam 
significar diminuição de produtividade. Dessa forma, supõese que as PcD física possam ter melhores condições e melhor aceitação no ambiente de trabalho, fazendo com que atribuam melhores significados ao seu trabalho.

\section{Suporte social e organizacional}

A análise dos resultados acerca do suporte social e organizacional no trabalho permitiu identificar as configurações dos suportes percebidos pelas pessoas com deficiência em relação às organizações que trabalham.

A maior média foi atribuída ao Suporte Emocional $(M=$ $3,58)$, seguida pelo Suporte Instrumental $(M=3,54)$ e, por último, o Suporte Informacional $(M=3,40)$. Para fins de correlação, uma pesquisa com trabalhadores não PcD de empresas privadas e públicas na região do Triângulo Mineiro (Moraes, 2007) forneceu médias para suporte social instrumental de 2,96, para o suporte social emocional de 2,90 e para o suporte social informacional de 2,78. Outra pesquisa, realizada na região Sul do país com bancários (Andrade, 2010), teve como resultado a média de 3,33 para suporte social instrumental, 3,28 para o suporte social emocional e de 3,54 para o suporte social informacional. Dessa forma, conclui-se que outras pesquisas têm encontrado médias próximas às obtidas neste trabalho, o que indica que a percepção de suporte social independe do fato de ter deficiência ou não.

Nesta pesquisa, maiores médias foram atribuídas ao suporte social instrumental pelos funcionários com deficiência física, com idade inferior a 30 anos e empregados na mesma empresa por prazos inferiores há cinco anos. Em relação ao suporte informacional, sua percepção é maior quando os funcionários têm idade inferior a 30 anos, escolaridade mais baixa ou trabalham na mesma empresa há menos de 5 ou há mais de 16 anos.

Os resultados também indicaram que as pessoas com deficiência, no geral, revelam uma percepção de neutralidade ou não posicionamento em relação ao suporte organizacional. Numa escala de cinco pontos, a percepção de suporte organizacional apresenta uma média geral de 3,34, média semelhante obtida por Andrade (2010) com amostra de bancários que não possuem deficiência $(M=3,17)$. As análises comparativas entre o perfil dos participantes e a percepção de suporte organizacional identificaram que esta é maior para aqueles que estão na empresa por tempo menor que cinco anos ou maior que 16 anos. Além disso, constatou-se que as $\mathrm{PcD}$ que trabalham na região Nordeste e Sudeste (com médias de 3,74 e 3,46, respectivamente, numa escala de 1 a 5) possuem uma melhor percepção de suporte organizacional do que aquelas com vínculo em empresas de outras regiões do país, nas quais os participantes tenderam à média 3 (voltada à neutralidade ou ao não posicionamento em relação aos aspectos pesquisados).

\section{Associações entre os construtos}

Com o objetivo de verificar se existe relação entre o suporte social e organizacional e o significado do trabalho real (categorias dos atributos descritivos), foram realizadas análi- ses estatísticas multivariadas por meio da análise de regressão linear múltipla. Considerando que os significados atribuídos ao trabalho real se concentraram principalmente em três categorias de atributos descritivos: 'Condições de trabalho', 'Sobrevivência pessoal e familiar' e 'Carga de trabalho', essas variáveis foram analisadas para identificar as possíveis relações de dependência com os vários tipos de suporte e também com as variáveis sociodemográficas.

Os modelos de regressão foram construídos por meio do método stepwise, no qual a seleção de entrada das variáveis preditivas é feita estatisticamente, e não tendo como base hipóteses teóricas prévias. Adotou-se o valor de 0,10 como probabilidade de entrada de uma variável no modelo e 0,20 como probabilidade de saída de uma variável.

Para cada categoria foram realizadas duas análises de regressão. Na primeira foram utilizadas as variáveis 'Suporte Social', dividido em suas três categorias: emocional, instrumental e informacional; e o 'Suporte Organizacional'. Na segunda, foram introduzidas as variáveis sociodemográficas: sexo (0: feminino; 1: masculino), estado civil (0: outros; 1 : casado), idade (0: até 30 anos; 1: de 31 a 50 anos; 2: acima de 50 anos), escolaridade (0: até ensino médio incompleto; 1 :ensino médio completo até superior incompleto; 2: a partir de superior completo), função do cargo (0: administrativo; 1: técnico; 2: técnico profissional; 3: gestão), tempo de empresa (0: até 5 anos; 1 : 6 a 15 anos; 2: acima de 15 anos), tipo de deficiência (0: física; 1: visual; 2: auditiva) e região do país (0: sudeste; 1 : sul; 2 : norte; 3: nordeste; 4: centro-oeste). Assim, a diferença no percentual explicado ( $R^{2}$ ajustado) quando se compara a segunda etapa da análise com a primeira indica o quanto as variáveis sociodemográficas acrescentam ao modelo explicativo das categorias dos atributos descritivos, para além do que os tipos de suporte já explicaram.

Para as análises de regressão referentes aos três fatores, foi identificada a normalidade dos modelos de explicação. O teste de Kolmogorov-Smirnov apresentou, respectivamente, Bloco 1 $\operatorname{com} p=0,632$ e Bloco 2 com $p=0,566$ ('Condições de Trabalho'), Bloco 1 com $p=0,172$ e Bloco 2 com $p=0,337$ ('Sobrevivência pessoal e familiar') e Bloco $1 \operatorname{com} p=0,705$ e Bloco 2 com $p=0,762$ ('Carga de trabalho'); confirmando a hipótese de normalidade dos resíduos, o que respalda os resultados da regressão.

Os resultados das análises de regressão para o fator 'Condições de Trabalho' apresentados na Tabela 1 mostram que o suporte social instrumental, o suporte social informacional e o suporte organizacional têm grande poder explicativo sobre esse fator, sendo responsáveis por $53,2 \%\left(R^{2}\right.$ ajustado $\left.=0,532\right)$ da variância dos resultados. Isso demonstra que as crenças do empregado de que a organização o provê de recursos e possui uma rede comum de comunicações que veicula informações precisas e confiáveis o faz sentir-se seguro, assistido e amparado socialmente. Desse modo, verifica-se que a atribuição de significado do trabalho relacionado à 'condição de trabalho' depende da percepção de suporte organizacional, suporte social instrumental e informacional. 
Tabela 1

Análise de Regressão para os Fatores Condições de Trabalho, Sobrevivência Pessoal e Familiar e Carga de Trabalho

\begin{tabular}{|c|c|c|c|c|c|c|c|c|c|}
\hline \multicolumn{10}{|c|}{ Bloco 1} \\
\hline \multirow[b]{2}{*}{ Variáveis Preditivas } & \multicolumn{3}{|c|}{ Condições de trabalho $^{1}$} & \multicolumn{3}{|c|}{ Sobrevivência pessoal e familiar ${ }^{2}$} & \multicolumn{3}{|c|}{ Carga de trabalho $^{3}$} \\
\hline & Beta & $\begin{array}{c}\text { Erro } \\
\text { Padrão }\end{array}$ & $\begin{array}{c}\text { Beta } \\
\text { Padronizado } \\
\end{array}$ & Beta & $\begin{array}{c}\text { Erro } \\
\text { Padrão }\end{array}$ & $\begin{array}{c}\text { Beta } \\
\text { Padronizado }\end{array}$ & Beta & $\begin{array}{c}\text { Erro } \\
\text { Padrão }\end{array}$ & $\begin{array}{c}\text { Beta } \\
\text { Padronizado } \\
\end{array}$ \\
\hline Constante & 0,887 & 0,183 & & 1,849 & 0,179 & & 0,887 & 0,183 & \\
\hline Suporte Social Instrumental & 0,172 & 0,074 & $0,180^{*}$ & 0,244 & 0,07 & $0,327 *$ & & & \\
\hline Suporte Social Informacional & 0,263 & 0,072 & $0,321 * *$ & 0,161 & 0,06 & $0,251^{*}$ & 0,263 & 0,072 & $0,321^{* *}$ \\
\hline Suporte Organizacional & 0,225 & 0,058 & $0,316^{* *}$ & & & & & & \\
\hline \multicolumn{10}{|c|}{ Bloco 2} \\
\hline \multirow[b]{2}{*}{ Variáveis Preditivas } & \multicolumn{3}{|c|}{ Condições de trabalho $^{4}$} & \multicolumn{3}{|c|}{ Sobrevivência pessoal e familiar ${ }^{5}$} & \multicolumn{3}{|c|}{ Carga de trabalho $^{6}$} \\
\hline & Beta & $\begin{array}{c}\text { Erro } \\
\text { Padrão }\end{array}$ & $\begin{array}{c}\text { Beta } \\
\text { Padronizado } \\
\end{array}$ & Beta & $\begin{array}{c}\text { Erro } \\
\text { Padrão }\end{array}$ & $\begin{array}{c}\text { Beta } \\
\text { Padronizado } \\
\end{array}$ & Beta & $\begin{array}{c}\text { Erro } \\
\text { Padrão }\end{array}$ & $\begin{array}{c}\text { Beta } \\
\text { Padronizado } \\
\end{array}$ \\
\hline Constante & 0,719 & 0,195 & & 1,730 & 0,177 & & 2,396 & 0,174 & \\
\hline Suporte Social Instrumental & 0,183 & 0,072 & $0,192 *$ & 0,248 & 0,068 & $0,332 * *$ & & & \\
\hline Suporte Social Informacional & 0,272 & 0,071 & $0,333^{* *}$ & 0,168 & 0,058 & $0,262 *$ & 0,203 & 0,046 & $0,335^{* *}$ \\
\hline Suporte Organizacional & 0,220 & 0,056 & $0,309^{* *}$ & & & & & & \\
\hline Sexo & 0,209 & 0,071 & $0,155^{*}$ & 0,227 & 0,067 & $0,215^{*}$ & 0,130 & 0,073 & 0,130 \\
\hline Função do cargo - Técnico & 0,044 & 0,077 & 0,033 & & & & & & \\
\hline Função do cargo - Téc. Profissional & 0,275 & 0,115 & $0,131^{*}$ & & & & & & \\
\hline Função do cargo - Gestão & $-0,067$ & 0,111 & $-0,034$ & & & & & & \\
\hline Tempo de organização - De 6 a 15 anos & & & & & & & 0,213 & 0,077 & $0,216^{*}$ \\
\hline Tempo de organização - Mais de 15 anos & & & & & & & $\begin{array}{l}- \\
0,102\end{array}$ & 0,119 & $-0,065$ \\
\hline
\end{tabular}

Nota: ${ }^{* *} \mathrm{p}<0,001 .{ }^{*} \mathrm{p}<0,05 . \mathrm{R}^{2}$ ajustado: ${ }^{1} 0,532 ;{ }^{2} 0,560 ;{ }^{3} 0,278 ;{ }^{4} 0,321 ;{ }^{5} 0,062 ;{ }^{6} 0,119$.

Quando se insere nessa análise de regressão os fatores sociodemográficos (Tabela 1 - Bloco 2), verifica-se um acréscimo do poder explicativo do modelo $\left(R^{2}\right.$ ajustado $\left.=0,560\right)$. Esse resultado sugere que a pessoa ser sexo feminino e possuir função do cargo Técnico profissional (comparado com as que possuem função Administrativa), possuem uma percepção maior do fator condições de trabalho. Nesta pesquisa, a função administrativa compreendeu, por exemplo, os cargos de assistente administrativo, auxiliar de operações, assistente de atendimento, etc. O grupo de profissionais no nível técnico profissional abrangeu as funções que exigem curso superior, como arquitetos, engenheiros e psicólogos. Assim, pode-se afirmar que ser mulher e ter uma função que exige curso superior aumenta a percepção do fator Condições de trabalho, relacionado à presença no trabalho de equipamentos adequados, segurança, higiene, assistência e amparo social.

Ao se submeter o fator 'Sobrevivência pessoal e familiar' às análises, verifica-se que o suporte social instrumental e o suporte social informacional explicam $27,8 \%$ da variância do modelo ( $R^{2}$ ajustado = 0,278), conforme Bloco 1 da Tabela 1 .

Quando a variável sexo é inserida, verifica-se um pequeno acréscimo no poder explicativo do modelo $\left(R^{2}\right.$ ajustado $=$ $0,321)$. Assim, verifica-se que a atribuição de significado do trabalho relacionado à 'sobrevivência pessoal e familiar' dependeu da percepção de suporte social instrumental e informacional, como também o sexo. Pode-se inferir que as mulheres com alta percepção de suporte social instrumental (a organização provê recursos materiais, financeiros, técnicos e gerenciais) e suporte social informacional (percepção do empregado de que a organização possui uma rede de comunicações comum que veicula informações precisas e confiáveis) são as que mais percebem a garantia de condições econômicas de sobrevivência e de sustento pessoal e familiar através do trabalho, além da estabilidade no emprego por meio do salário e do progresso social.

Nos resultados das análises de regressão para o fator 'Carga de trabalho', apenas o suporte social informacional tem um pequeno poder explicativo na variância do modelo $\left(R^{2}\right.$ ajustado $=0,062)$ no Bloco 1 (Tabela 1 ). Quando as variáveis sociodemográficas sexo e tempo de organização são inseridas, verifica-se um aumento no poder explicativo do modelo, que passa a ser de quase $12 \%\left(R^{2}\right.$ ajustado $\left.=0,119\right)$.

Assim, estar na organização num período entre 6 e 15 anos (comparados com o grupo que está na organização há menos de 5 anos) aumenta a percepção do fator 'Carga de Trabalho', que descreve o trabalho como representando ocupação, esforço mental, tarefas repetidas e exigência de ritmo.

Faz-se necessário comentar que o 'Suporte Social Emocional' não apareceu como variável preditiva em nenhuma análise de 
regressão. Em contrapartida, o fator sociodemográfico 'sexo' esteve presente nas três análises de regressão, indicando que as mulheres - quando comparadas com os homens - possuem uma maior percepção desses fatores. As mudanças nos últimos anos nos conceitos legais e morais a respeito dos direitos no trabalho, inclusive às mulheres, têm alterado substancialmente as políticas dentro das organizações. Por consequência, o significado do trabalho para este grupo provavelmente está sendo redimensionado. Essa pesquisa mostrou que o gênero foi um fator determinante na percepção dos fatores descritivos do trabalho.

\section{Conclusões}

O presente estudo permitiu verificar que os significados atribuídos ao trabalho pelas $\mathrm{PcD}$ estão predominantemente associados às características concretas de "Condições de trabalho' (condições para o exercício das atividades e condições de segurança), 'Sobrevivência pessoal e familiar' (sustento) e 'Carga de trabalho (tarefas repetidas e responsabilidades), sendo que grande parte dessas pessoas estão agrupadas segundo características de significados associados a questão do trabalho apenas como garantia de reprodução da vida. Esses resultados refletem as exigências do mundo do trabalho e da divisão de tarefas que tem colocado as PcD's em funções mais repetitivas (Ribeiro \& Carneiro, 2009).

Além disso, foi possível verificar que os fatores de 'suporte informacional' e de 'suporte instrumental' estão relacionados com o significado do trabalho concreto para pessoas com deficiência, ficando clara a importância de considerar esses aspectos de contexto organizacional na explicação do significado atribuído ao trabalho por PcD.

Em síntese, a ausência de compartilhamento de informações (relacionada ao suporte informacional) e de adaptações materiais (relacionada ao suporte instrumental) pode influir no significado atribuído ao trabalho e, possivelmente, no desempenho das PcD. Assim, não oferecer as condições adequadas de trabalho e não investir nas adaptações necessárias implica em negar às pessoas com deficiência a possibilidade de atribuir significados mais positivos ao trabalho e, por extensão, retiram delas a possibilidade de dar um significado ao próprio ato de viver, conforme argumento defendido por Brief e Nord (1990). Parece indispensável, portanto, a necessidade da organização assimilar e comunicar informações de modo confiável, oferecer insumos materiais e técnicos, cumprir as obrigações financeiras e atentar para práticas que propiciem a edificação de políticas claras, clima de confiança e apoio para que as pessoas com deficiência possam reconhecer suporte no ambiente laboral e, assim, exercerem o direito a um trabalho que tenha sentido para elas. Pesquisas realizadas em empresas têm apontado a importância da adaptação das condições e instrumentos de trabalho segundo as necessidades específicas de cada pessoa (Carvalho-Freitas, Toledo, Nepomuceno, Suzano, \& Almeida, 2010; Tanaka \& Manzini, 2005;).
Outras pesquisas, sustentadas na mesma abordagem metodológica adotada na presente pesquisa, seriam recomendadas para aplicação em amostras maiores e em outros ambientes, para uma melhor caracterização das potenciais diferenças de percepção dos construtos analisados em relação particularmente à natureza do trabalho realizado, ao grau de escolaridade da PcD e ao tipo de deficiência que esta apresenta.

\section{Agradecimento}

Agradecimentos ao CNPq pelo apoio ao financiamento da pesquisa.

\section{Referências}

Andrade, T. (2010). Valores organizacionais, suporte social e organizacional no trabalho: Um estudo no setor bancário. (Dissertação de Mestrado). Universidade Federal de Santa Maria, Santa Catarina. doi: 10.5329/ RECADM.2013003)

Borges, L. O. (1998). O Significado do trabalho e a socialização organizacional: Um estudo empírico entre trabalhadores da construção habitacional e de redes de supermercados (Tese de Doutorado não publicada). Universidade de Brasília, Distrito Federal.

Borges, L. O., \& Alves-Filho, A. (2003). A estrutura fatorial do inventário do significado e motivação do trabalho, IMST. Avaliação Psicológica, 2(2), 123-145. Recuperado de http://pepsic.bvsalud.org/scielo.php?script=sci_ arttext\&pid=S1677-04712003000200004\&lng=pt\&tlng=pt. .

Borges, L. O., \& Tamayo, A. (2001). A estrutura cognitiva do significado do trabalho. Revista Psicologia: Organizações e Trabalho, 1(2), 11-44. Recuperado de http://pepsic.bvsalud.org/scielo.php?script=sci arttext\&pid=S1984-66572001000200002\&lng=pt\&tlng=pt. .

Borges, L. O., \& Yamamoto, O. (2010). O significado do trabalho para psicólogos brasileiros. In A. V. B. Bastos; S. M. G. Gondim \& cols. (2010), O trabalho do psicólogo no Brasil. Porto Alegre: Artmed, 248-282.

Borges, L. O., Tamayo, A., \& Alves Filho, A. (2005). Significado do trabalho entre profissionais de saúde. In L. O. Borges (Org.), Os profissionais de saúde e seu trabalho. São Paulo: Casa do Psicólogo

Brief, A. P., \& Nord, W. R. (1990). Meanings of occupational work: A collection of essays. Lexington: Lexington Books.

Carvalho-Freitas, M. N., Silva, L. M., Farias, S. P. M., Oliveira, M. S., \& Tette, R. P. G. (2013). Comprometimento organizacional e qualidade de vida no trabalho para pessoas com e sem deficiência. Psico-USF, Itatiba, 18(1), 109-120. doi: 10.1590/S1413-82712013000100012

Carvalho-Freitas, M. N., Toledo, I., Nepomuceno, M., Suzano, J., \& Almeida, L. (2010 jul/set). Socialização organizacional de pessoas com deficiência. Revista Administração de Empresas, 50(3), 264-275. doi: 10.1590/S003475902010000300003

Cohen, S. (2004). Social relations and health. American Psychologist, 59, 676684. doi: http://psycnet.apa.org/doi/10.1037/0003-066X.59.8.676

Eisenberger, R., Huntington, R., Hutchison, S., \& Sowa, D. (1986). Perceived organizational support. Journal of Applied Psychology, 71(3), 500-507. doi: http://psycnet.apa.org/doi/10.1037/0021-9010.71.3.500

Gomes, J. F. B. (2009). Contribuições da categoria trabalho na formação da identidade da pessoa com deficiência (Dissertação de Mestrado). Pontifícia Universidade Católica de Minas Gerais, Minas Gerais. Recuperado de http://www.pucminas.br/documentos/dissertacao_jaqueline_fiqueiredo. pdf

Gomide Jr., S., Guimarães, L., \& Damásio, L. (2004). Construção e validação de um instrumento de medida de percepção de suporte social no trabalho. II Seminário de Pesquisa do Grupo Interinstitucional de Pesquisa em Bem-estar e Suporte Social e Trabalho, Uberlândia. 
Gomide Jr., S., Guimarães, L., \& Damásio, L. (2008). Construção e Validação da Escala de Percepção de Suporte Social no Trabalho - EPSST. In M. M. M. Siqueira (Org.). Medidas de comportamento organizacional: Ferramentas de diagnóstico e de gestão. Porto Alegre: Artmed, 286-292

Gouldner, A.W. (1960). The norm of reciprocity: A preliminary statement. American Social Review, 25(2), 161-178. Recuperado de http://hdl.handle. net/10694/347

Instituto Brasileiro de Geografia e Estatística (2010). Pesquisa nacional por amostra de domicílios. Rio de Janeiro: IBGE. Recuperado de http://www. ibge.gov.br/home/ estatistica/populacao.

Instituto Ethos (2010). Perfil social, racial e de gênero das 500 maiores empresas do Brasil e suas ações afirmativas. Recuperado de http://www1.ethos.org. br/EthosWeb/aqruvio/0-A-eb4Perfil_2010.pdf.

Lei n. 8.112, de 11 de dezembro de 1990. (1990, 11 de dezembro). Dispõe sobre o regime jurídico dos servidores públicos civis da União, das autarquias e das fundações públicas federais. Recuperado de http://www.planalto.gov. br/ccivil_03/leis/18112cons.htm

Lei n. 8.213, de 24 de julho de 1991. (1991, 24 de julho). Dispõe sobre os Planos de Benefícios da Previdência Social, e dá outras providências. Recuperado de www.planalto.gov.br/ccivil_03/Leis/L8213cons.htm

Ministério do Trabalho e Emprego. (2011). Características do emprego formal segundo a Relação Anual de Informações Sociais. Recuperado de http://www. mte.gov.br/rais/2010/arquivos/Resultados_Definitivos.pdf

Moraes, E. R. (2007). Percepções de suporte organizacional e social no trabalho como antecedentes da percepção de saúde da organização. (Dissertação de Mestrado). Universidade Federal de Uberlândia, Minas Gerais. Recuperado de http://repositorio.ufu.br/bitstream/ 123456789/1543/1/Percep\%C3 $\% \mathrm{~A} 7 \% \mathrm{C} 3 \% \mathrm{~B} 5$ esSuportesOrganizacional.pdf

MOW International Research Team. (1987). The meaning of working. Londres: Academic Press.

Organização Internacional do Trabalho (OIT). (2009). Disability and work. Secretaria Internacional do Trabalho. Brasília: DF. Recuperado de http:// www.planalto.gov.br/ccivil_03/LEIS/L9029.HTM

Oliveira-Castro, G. A., Pilati, R., \& Borges-Andrade, J. E. (1999). Percepção de suporte organizacional: Desenvolvimento e validação de um questionário. Revista Administração Contemporânea, 3(2). doi: 10.1590/S141565551999000200003

Pereira, C. S., Del Prette, A., \& Del Prette, Z. A. P. (2008). Qual o significado do trabalho para as pessoas com e sem deficiência física? Psico-USF, 13(1), 105-114. doi: 10.1590/S1413-82712008000100013

Rhoades, L., \& Eisenberger, R. (2002). Perceived organizational support: A review of the literature. Journal of Applied Psychology, 87(4), 698-714. doi: http://psycnet.apa.org/doi/10.1037/0021-9010.87.4.698

Rodriguez, M. S., \& Cohen, S. (1998). Social support. Encyclopedia of Mental Health (Vol. 3, pp. 535-544). Nova Iorque: Academic Press.

Ribeiro, M. A., \& Carneiro, R. (2009). A inclusão indesejada: As empresas brasileiras face à Lei de Cotas para pessoas com deficiência no mercado de trabalho. Revista Organização \& Sociedade, 16(50), 545-564. Recuperado de http://www.portalseer.ufba.br/index.php/revistaoes/article/view/11036

Schur, L.; Kruse, D.; \& Blanc, P. (2005). Corporate culture and the employment of persons with disabilities. Behavioral Sciences and the Law, 23(1), 3-20. doi: $10.1002 / \mathrm{bsl} .624$

Secretaria Internacional do Trabalho. (2006). Gestão de questões relativas à deficiência no local de trabalho: Repertório de recomendações práticas da OIT. (1 ${ }^{\mathrm{a}}$. ed., E. A. Cunha, Trad.; J. B. C. Ribas, Rev. Tec.). Brasília: OIT

Siqueira, M. M. M. (1995). Antecedentes de comportamentos de cidadania organizacional: A análise de um modelo pós-cognitivo. (Tese de Doutorado não publicada). Universidade de Brasília, Distrito Federal.

Siqueira, M. M. M., \& Gomide Júnior, S. (2008). Suporte no trabalho. In: M. M. M. Siqueira (Org.) Medidas do Comportamento Organizacional: ferramentas de diagnóstico e de gestão. Porto Alegre: Artmed.

Soares, C. R. V. (1992). Significado do trabalho: Um estudo comparativo de categorias ocupacionais. (Dissertação de Mestrado). Universidade de Brasília, Distrito Federal. doi: 10.1590/S0034-75901995000600004
Suzano, J. C. C. (2011). Concepções de deficiência e percepções de desempenho por tipo de deficiência: A perspectiva dos gestores (Dissertação de Mestrado não publicada). Universidade Federal de São João del-Rei, São João del-Rei.

Tanaka, E. D. O., \& Manzini, E. J. (2005). O que os empregadores pensam sobre o trabalho da pessoa com deficiência? Revista Brasileira de Educação Especial, 11(2), 273-294. doi: 10.1590/S1413-65382005000200008

Varella, J. M. C. (2006). A motivação e o significado do trabalho para bancários: Estudo comparativo entre dois momentos no processo de reestruturação produtiva. (Dissertação de Mestrado). Universidade Federal do Rio Grande do Norte, Natal. Recuperado de ftp://ftp.ufrn.br/_pub/biblioteca/ext/ bdtd/JanineMCV.pdf

Vilela, E. C. (2003). Significado do trabalho e escolha acadêmico-profissional: Um estudo com universitários primeiranistas. (Dissertação de Mestrado). Universidade Federal do Rio Grande do Norte, Natal. Recuperado de ftp:// ftp.ufrn.br/pub/biblioteca/ext/bdtd/ElsonCV.pdf

Violante, R. R., \& Leite, L. P. (2011). Employment of people with disability: An analysis of social inclusion in the job market in the city of Bauru, SP. Cadernos de Psicologia Social do Trabalho, 14(1), 73-91. Recuperado de http://pepsic.bvsalud.org/scielo.php?script=sci_arttext\&pid=S151637172011000100007\&lng=pt\&tlng=pt 
Raissa Pedrosa Gomes Tette, Mestre em Psicologia pela Universidade Federal de São João del Rei - UFSJ. Endereço para correspondência: Rua Expedicionário Raimundo Benedito da Silva, 90, Vila Belizário, São João Del Rei. Telefones: (32) 3371-7861/ (32) 8821-4150. E-mail: raissatette@yahoo.com.br

Maria Nivalda de Carvalho-Freitas, Doutora em Administração pela Universidade Federal de Minas Gerais - UFMG, é Professora adjunta na Universidade Federal de São João del Rei - UFSJ. E-mail: nivalda@ufsj. edu.br

Marcos Santos de Oliveira, Doutor em Estatística e Experimentação Agropecuária pela Universidade Federal de Lavras - UFLA, é Professor adjunto na Universidade Federal de São João del Rei - UFSJ. E-mail: mso@ufsj.edu.br 